\title{
SIMPLIFICATION OF EARTHQUAKE ACCELEROGRAMS FOR RAPID TIME HISTORY ANALYSIS BASED ON THE IMPULSIVE LOAD CONCEPT
}

\author{
Mahmood Hosseini ${ }^{1}$ and Iman Mirzaei ${ }^{2}$ \\ ${ }^{1}$ Associate Prof., Structural Eng. Research Center, Int'1 Inst. of Earthquake Eng. and Seismology \\ (IIEES), Tehran, Iran \\ Email: hosseini@iiees.ac.ir \\ ${ }^{2}$ Graduate Student, Earthquake Eng. Dept., Science and Research Branch of the Islamic Azad \\ University (IAU), Tehran, Iran \\ Email: Mirzaei.Iman@gmail.com
}

Keywords: Digitized accelerograms; Time history analysis; Time step size, Calculation time

\begin{abstract}
Regarding that the time history analysis, as the most realistic seismic response analysis method, is very time consuming, in this paper a method is proposed for simplification of digitized accelerograms by using the concept of impulsive load. In the proposed method, the accelerogram, which is actually a numerical array with the time step size of 0.02, 0.01 or even 0.005 seconds, and usually contains several thousands of time steps with their corresponding acceleration values, is substituted by a limited number (usually less than just a few hundreds) of discrete values, each one equivalent to the area created by the acceleration curve and the time axis between two of its subsequent zero-crossings. These discrete values, which are obviously positive and negative one after the other, multiplied by the mass of the SDOF system, can be considered as a series of impulsive loads, applied consequently to the system, which is subjected to the base acceleration. Using the simple formula of response to impulsive load, response of the SDOF system to base acceleration can be calculated as the summation of its responses to the series of impulsive loads, created by the described method for any given accelerogram. Several numerical examples are presented in the paper to show the efficiency of the proposed simplification technique. Numerical results show that the amount of error of peak response calculation is usually less than 5\% for most of earthquake records, while the required time for response calculations is generally only $10 \%$ of that of the conventional time history analysis, or even less than that.
\end{abstract}




\section{INTRODUCTION}

Time History Analysis (THA) has been known as the best tool for realistic seismic response analysis of structural systems. However, this type of analysis is very time consuming, mainly due to the very small time step size, used in digitizing the earthquake accelerograms. This is while usually the natural periods of structures are much larger than the digitized accelerogram's time step size. Therefore, if by some way the THA can be done with large time step size, it would be very helpful for quick seismic response analysis any type of structural systems.

A way for achieving this goal is the simplification of accelerograms for seismic response analyses, which goes back to early to mid 70s. Wang (1975) has worked on structural instability during earthquakes and accelerogram simplification [1]. Some simplified dynamic analysis methods have been also presented by researchers in recent years, but each one of them has been focused on some specific type of structures. For example, Kitiyodom and his colleagues (2004) have proposed a simplified dynamic analysis method for piled raft foundation subjected to earthquake load [2], and Ghafari Oskoei and McClure (2009) have presented some simplified dynamic analysis methods for guyed telecommunication masts under seismic excitation [3]. Some simplified THA methods have been also proposed in previous researches based on various means, including the one performed by Domingues Costa and his colleague in 2005 by using theory of plasticity [4].

Recently, Soroushian (2008) has presented a technique for the time integration analysis with steps larger than the excitation steps [5], in which the time step size can be chosen as large as five times of the usual time step size without remarkable error in response calculations. Finally, Faroughi and Hosseini (2011) have proposed a method for quick time history analysis of linear systems by using the modified Inverse Fourier Transform of the accelerogram [6], which makes it possible to perform the analysis by consuming only around $20 \%$ of the usual time of the conventional seismic response analysis, with a very little error, mostly less than $5 \%$.

In this paper a method is proposed for increasing the speed of response time history analyses by simplification of the earthquake acceleration digitized record based on using the concept of impulsive load, and the zero-crossing points of the record. By using this method, the required time for response time history analysis is reduced significantly (usually more than 10 times comparing to the conventional analyses), while the amount of error of the response calculations is less than $5 \%$ in most cases.

\section{THE METHOD}

In the proposed simplification method the continuous input accelerogram, which when digitized, is actually a numerical array with the time step size of $0.02,0.01$ or even 0.005 seconds, and usually contains several thousands of time steps with their corresponding acceleration values, is substituted by a limited number (usually less than just a few hundreds) of discrete values, each one equivalent to the area created by the acceleration curve and the time axis between two of its subsequent zero-crossings. These discrete values, which are obviously positive or negative one another, multiplied by the mass of the SDOF system, can be considered as a series of impulsive loads, applied consequently to the system, which is subjected to the base acceleration. Using the simple concept of the impulsive load, which is equivalent to a sudden change of the system's velocity, the response of the SDOF system with the mass of $m$, un-damped and damped frequencies of, respectively, $\omega_{N}$ and $\omega_{D}$ and damping ratio of $\xi$ to base acceleration, at the instant $t_{i+1}$ can be calculated as: 


$$
u\left(t_{i+1}\right)=e^{-\xi \omega_{\mathrm{N}} \Delta t_{i+1}}\left[\frac{\tilde{u}\left(t_{i}^{+}\right)+\xi \omega_{\mathrm{N}} u\left(t_{i}\right)}{\omega_{D}} \sin \omega_{D} \Delta t_{i+1}+u\left(t_{i}\right) \cos \omega_{D} \Delta t_{i+1}\right]
$$

where $t_{i}$ stands for the instant of applying the $i^{\text {th }}$ impulse, $\Delta t_{i+1}=t_{i+1}-t_{i}$ and $\dot{u}\left(t_{i}^{+}\right)$is the suddenly increased velocity of the system at instant $t_{i}$ just after applying the $i^{\text {th }}$ impulse, $\operatorname{Imp}_{i}$, and is given by:

$$
\dot{u}\left(t_{i}^{+}\right)=\dot{u}\left(t_{i}\right)+I m p_{i} / m
$$

In Equation (2) the velocity of the system at instant $t_{i}$ just before applying the $i^{\text {th }}$ impulse, $\dot{u}\left(t_{i}\right)$, is given by:

$$
\begin{aligned}
& \dot{u}\left(t_{i}\right)= \\
& -\xi \omega_{N} \Delta t_{i} e^{-\xi \omega_{N} \Delta t_{i}}\left[\frac{\dot{u}\left(t_{i-1}^{+}\right)+\xi \omega_{N} u\left(t_{i-1}\right)}{\omega_{D}} \sin \omega_{D} \Delta t_{i}+u\left(t_{i-1}\right) \cos \omega_{D} \Delta t_{i}\right]+e^{-\xi \omega_{N} \Delta t_{i}}\left\{\left[\dot{u}\left(t_{i-1}^{+}\right)+\right.\right. \\
& \left.\left.\xi \omega_{N} u\left(t_{i-1}\right)\right] \cos \omega_{D} \Delta t_{i}-\omega_{D} \sin \omega_{D} \Delta t_{i}\right\}
\end{aligned}
$$

where $\Delta t_{\bar{i}}=t_{\bar{i}}-t_{i-1}\left(t_{0}\right.$ is assumed to be zero). In Equation (2) the value of the $i^{\text {th }}$ impulse, $\operatorname{Imp}_{i}$, is defined by:

$$
\operatorname{Im} p_{i}=-m \int_{t_{z c, i-1}-1}^{t_{z e, i}} \ddot{u}_{g}(t) \cdot d t
$$

In Equation (4) $\ddot{u}_{g}(t)$ is the earthquake ground acceleration, and $t_{z c, i}$ is the $i^{\text {th }}$ zero-crossing of the $\ddot{u}_{g}(t)$ function. For the first instant $(i=1)$ the condition is expressed as $\dot{u}\left(t_{1}\right)=0$ and $\dot{u}\left(t_{1}^{+}\right)=I m p_{1} / m$. Obviously, at start it is assumed that $\dot{u}\left(t_{0}^{+}\right)=0$ and $u\left(t_{0}\right)=0$. To show the efficiency of the aforementioned formulation for the seismic response time history analysis of structural systems, several numerical examples are presented in the next section of the paper with regard to SDOF systems.

\section{NUMERICAL EXAMPLES}

To show the efficiency of the proposed method in rapid seismic response calculations the response histories of a set of SDOF systems, which cover a wide range of periods form 0.3 $\mathrm{sec}$ to $1.0 \mathrm{sec}$, have been calculated for a group of accelerograms with various frequency content from low to high, belonging to some well-known earthquakes, including El Centro, Cape Mendocino, Imperial Valley, Humbolt Bay Central California, and Kocaeli. These earthquakes cover a wide range of frequencies. In each case the response calculations have been performed once by using the original accelerogram and the conventional response calculation method, and once by using the simplified accelerogram and the propose formulations, and the two response histories have been compared. To show the capability of the proposed method in the full frequency range the displacement spectra of the used accelerograms have been obtained by using both conventional and the proposed method and have presented for comparison.

Figure 1 shows the accelerogram the main component of El Centro earthquake, as a sample, with its equivalent impulses, calculated by Equation 4, and to see better the details of the equivalent impulses, a small portion of Figure 1-(a) has been magnified as presented in Figure 1-(b). 


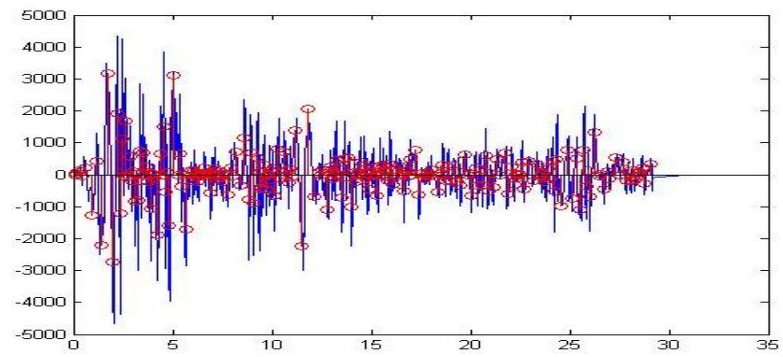

(a)

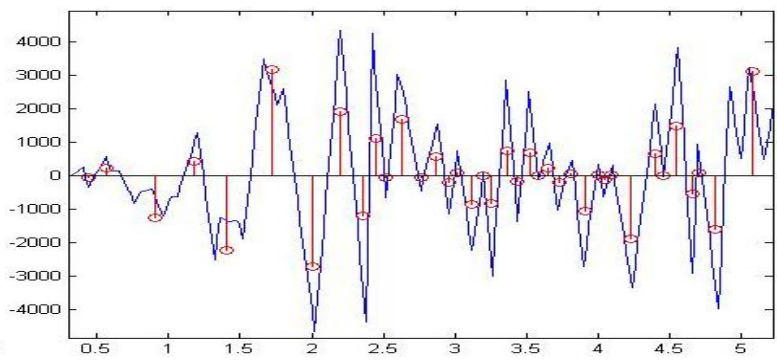

(b)

Figure 1. Accelerogram of the main component of El Centro earthquake and its equivalent impulses, (a), and a magnified portion of the accelerogram shown in Figure 1 with details of the equivalent impulses, (b)

As the first set of response calculation results the displacement response of a SDOF system with natural period of $0.5 \mathrm{sec}$ and damping ratio of $2 \%$ subjected to the main accelerogram of El Centro earthquake, calculated by the conventional response analysis method, and shown in Figure 2, has been calculated once more by the proposed method based on the simplified accelerogram, and the results are shown in Figures 3-a and 3-b, which show the responses obtained by simplifying the accelerogram respectively as single impulses between the subsequent zero-crossings, and double impulses between the subsequent zerocrossings.

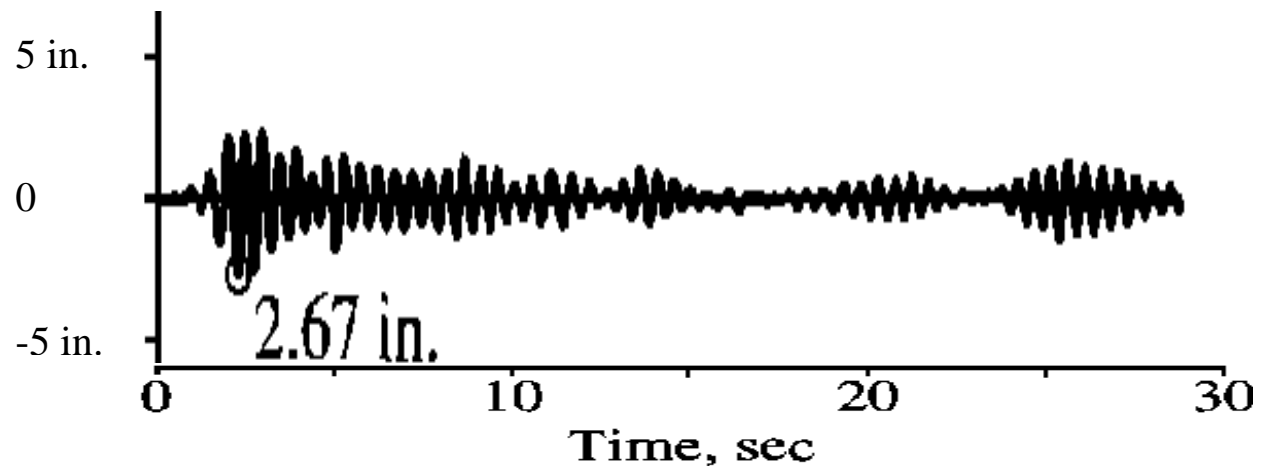

Figure 2. The displacement response history of a SDOF system with natural period of $0.5 \mathrm{sec}$ and damping ratio of $2 \%$ subjected to the accelerogram shown in Figure 1, obtained by the conventional analysis method

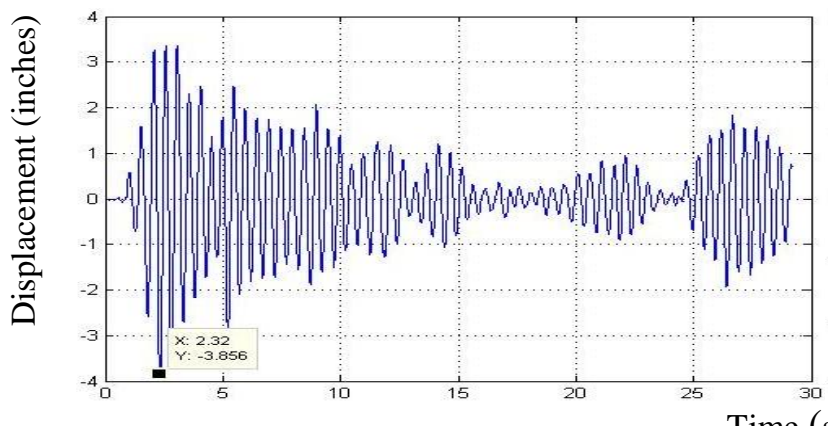

(a) By single impulse simplification

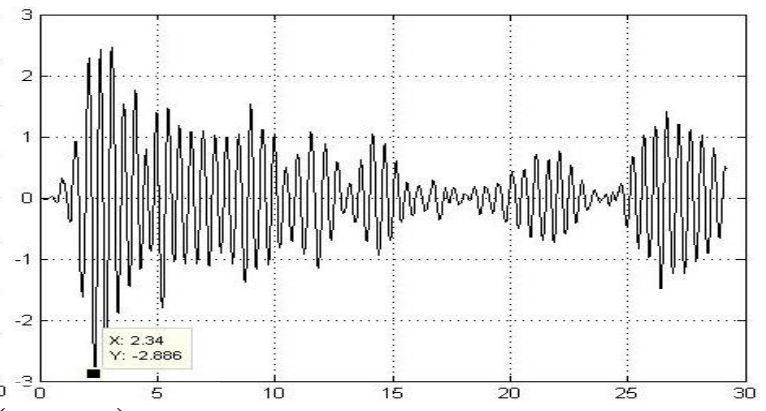

(b) By double impulses simplification

Figure 3. Displacement response histories of the SDOF system with natural period of $0.5 \mathrm{sec}$ and damping ratio

of $2 \%$ subjected to the accelerogram shown in Figure 1, calculated by the proposed method based on the simplified record as: (a) single impulses between subsequent zero-crossings, and (b) double impulses between subsequent zero-crossings

Comparing the response history shown in Figure 3-a with the one shown in Figure 2 it can be seen that by using the single impulse simplification of accelerogram, although the general trend of the response history is very similar to that of the exact response history, its peak 
value has around and $40 \%$ error. However, comparison of response history shown in Figure 3 -b with the one shown if Figure 3 indicates that by double impulse simplification of the accelerogram the amount of error will decrease to less than $7 \%$. It should be noted that in case of the SDOF system with the natural period of $0.5 \mathrm{sec}$ the relatively high level of error, particularly when single impulse simplification is used, is expected, since the nature of the proposed simplification method results in deletion of high frequencies or low periods of the accelerogram to some extent. On this basis, by increasing the natural period of the SDOF system, the level of error should decrease. This fact can be easily seen in the displacement response spectra of the employed accelerogram, developed by the exact and simplified methods, as shown Figures 4. Comparing the spectrum curves shown in Figures 4-b and 4-c with the one shown in Figure 4-a it can be seen that for a system with the natural period of 1.0 sec the amounts of error for the case of single impulse simplification and double simplification are respectively around $8 \%$ and $2 \%$.

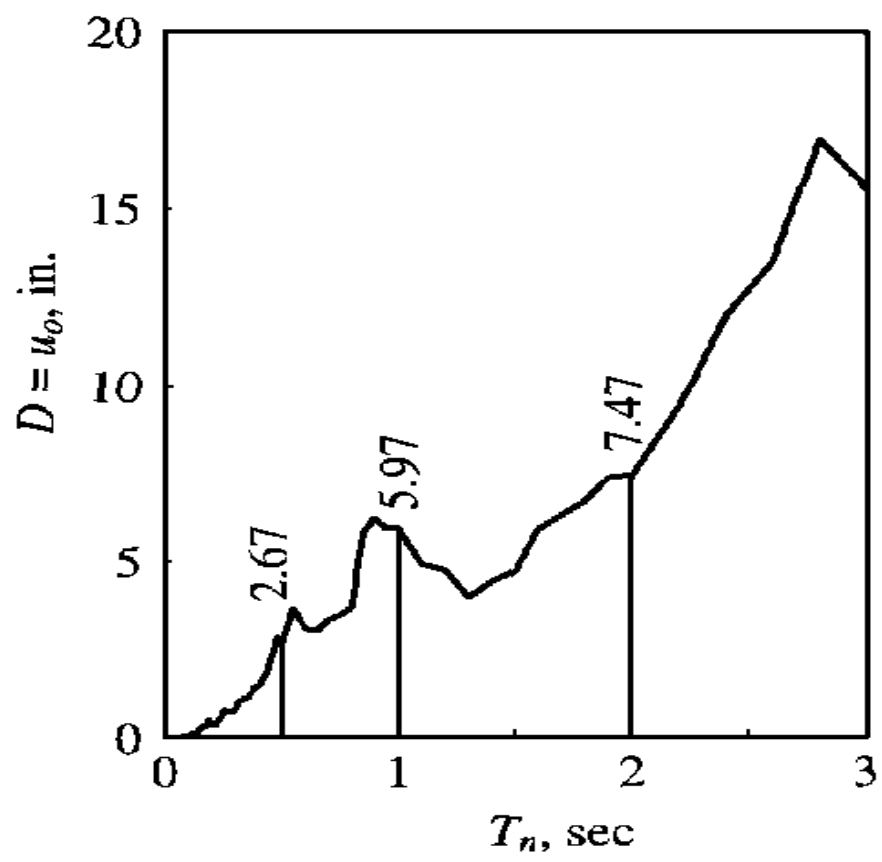

(a) The exact spectrum

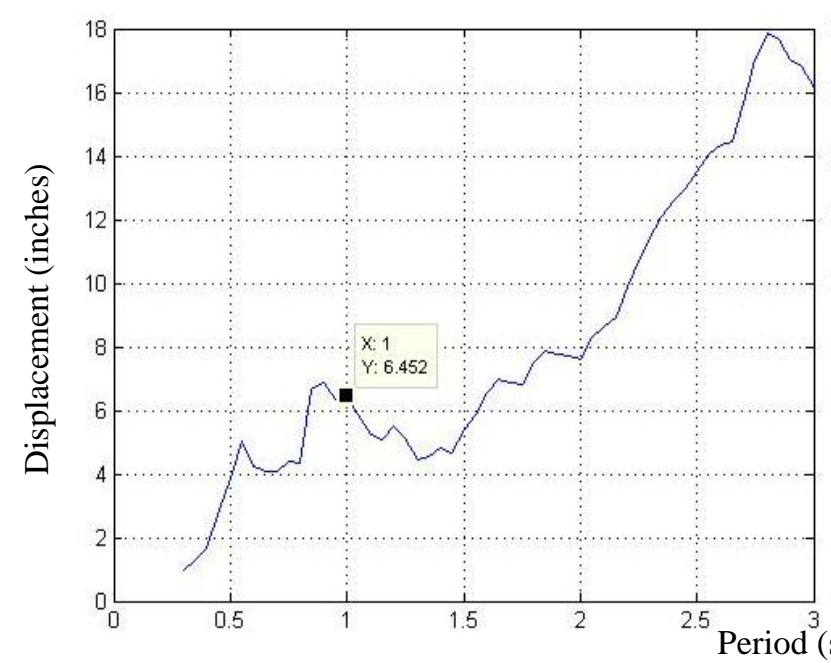

(b) By single impulse simplification

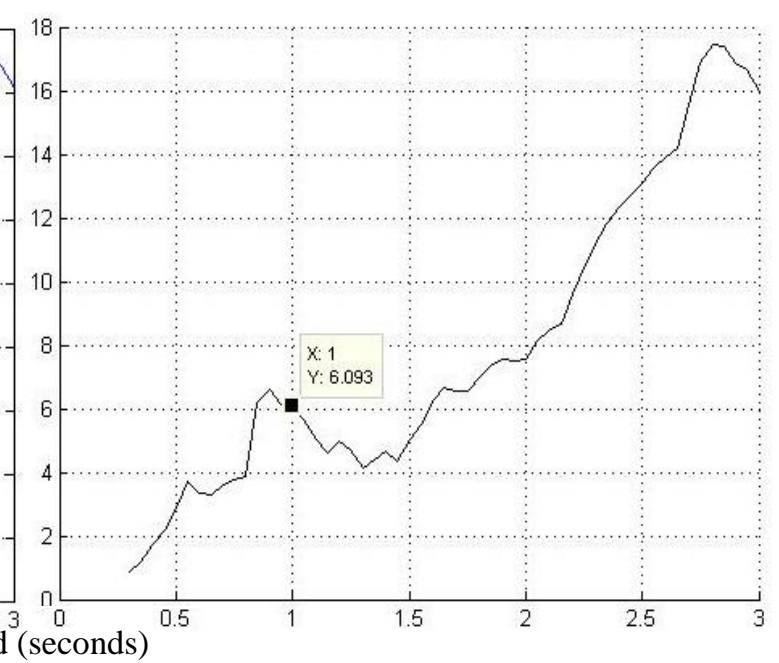

(c) By double impulses simplification

Figure 4. Displacement response spectra obtained by the original and simplified accelerograms 
To see better the difference between the spectrum obtained by the exact method and the one obtained by the simplified method, and also to realize the amounts of error in single impulse and double impulse simplifications all three spectra have been shown in one graph, shown in Figure 5-(a), and the amounts of error are shown in Figure 5-(b).

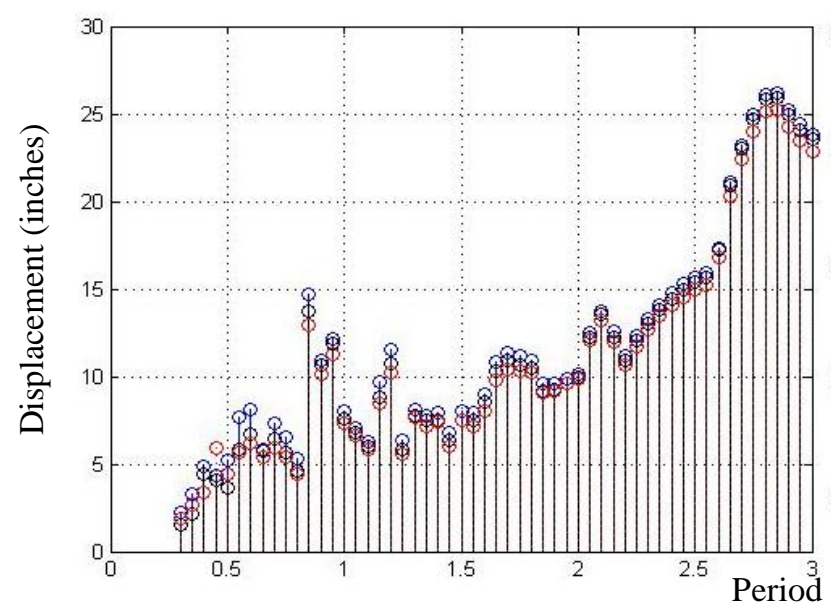

(a) Displacement response spectruı

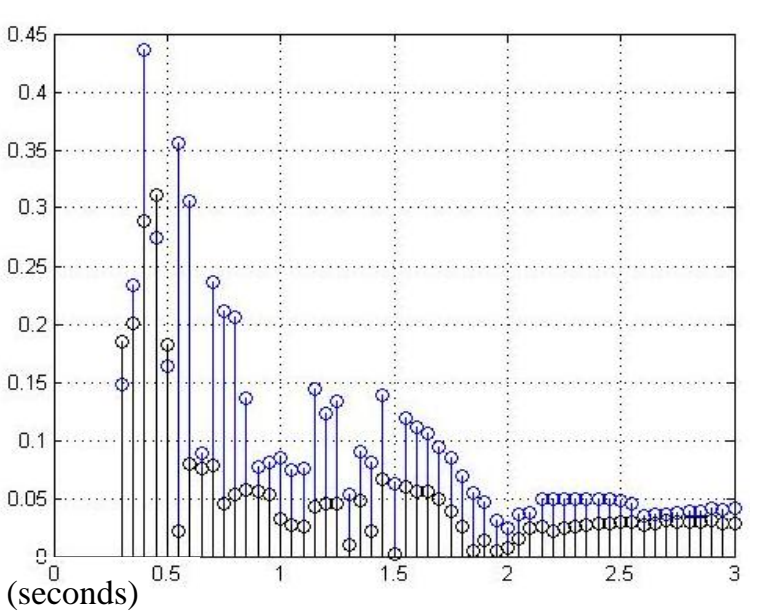

(b) The amount of error

Figure 5. Displacement response spectra (a) obtained by the original and simplified accelerograms, and the amounts of error (b) in cases of single- and double impulse simplification

In Figure 5-(a) the exact values are shown by red nuts, and the values obtained by singleand double impulse simplification are shown respectively by blue nut and black nuts. It is seen that single impulse simplification leads to higher spectral response comparing to double impulse simplification, and the latter leads to higher values than the exact values. In fact the proposed simplification method always results in overestimated displacement response, and therefore is a conservative simplification.

As other samples of the numerical results the displacement response spectra of some of the employed earthquakes accelerograms, developed by both the exact and the simplified methods, are presented in Figures 6 to 12, in which the result of the exact method is indicated by red curves, and those of the single- and double impulse simplification by, respectively, blue and black curves (more results of this type can not be presented here because of lack of space, and can be found in the main report of the study (Mirzaei 2013), [7]).
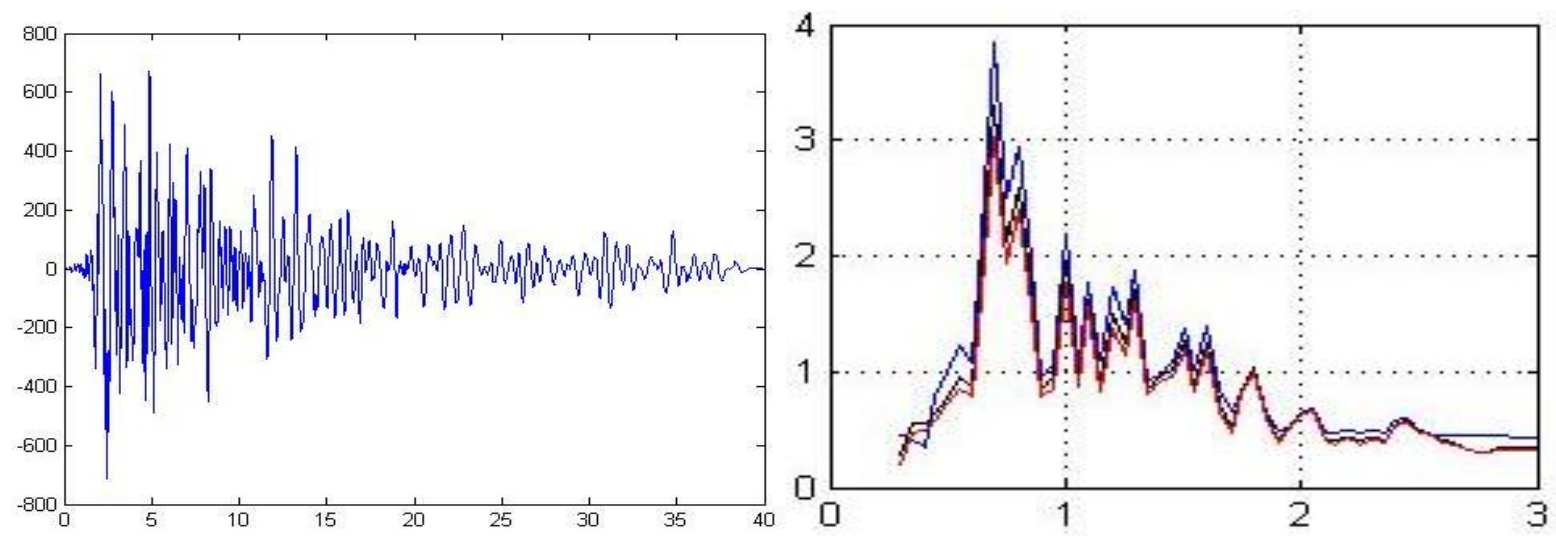

Figure 6. Accelerogram (in Gal units) and displacement spectra (in inches) of the Central Calif earthquake (longitudinal comp.) obtained by exact (in red) and simplified method (in blue and black) 

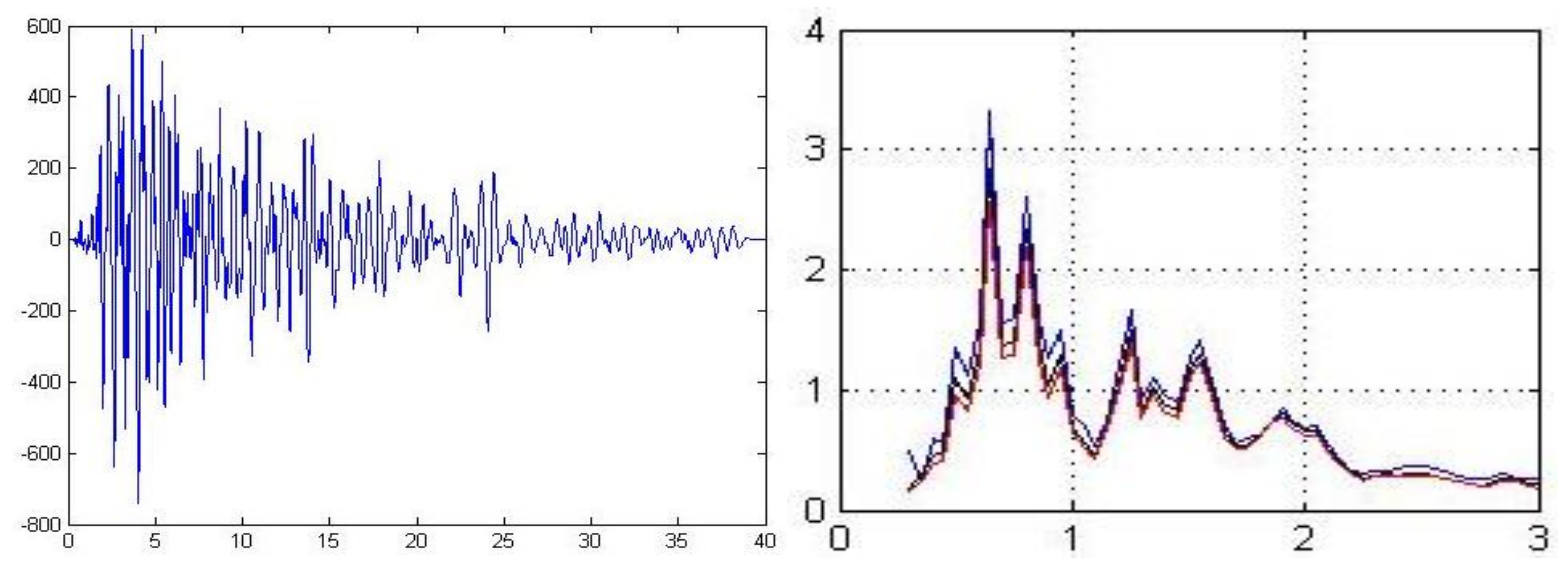

Figure 7. Accelerogram (in Gal units) and displacement spectra (in inches) of the Central Calif earthquake (transverse comp.) obtained by exact (in red) and simplified methods (in blue and black)
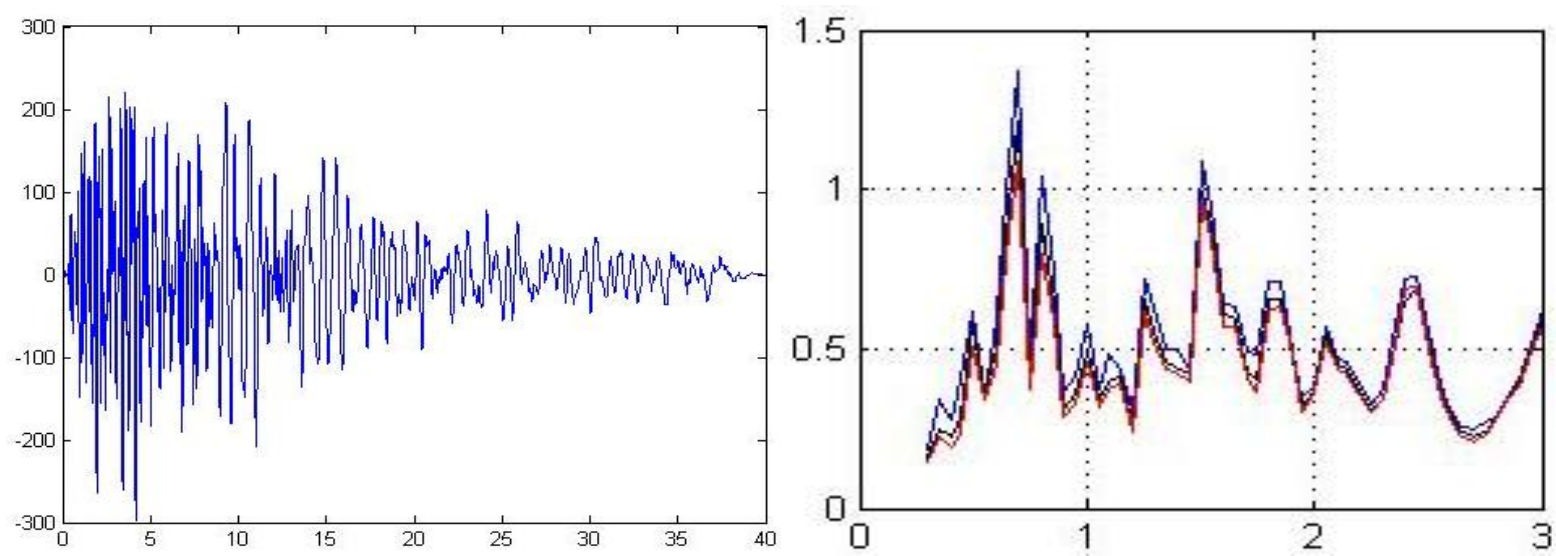

Figure 8. Accelerogram (in Gal units) and displacement spectra (in inches) of the Central Calif earthquake (vertical comp.) obtained by exact (in red) and simplified methods (in blue and black)
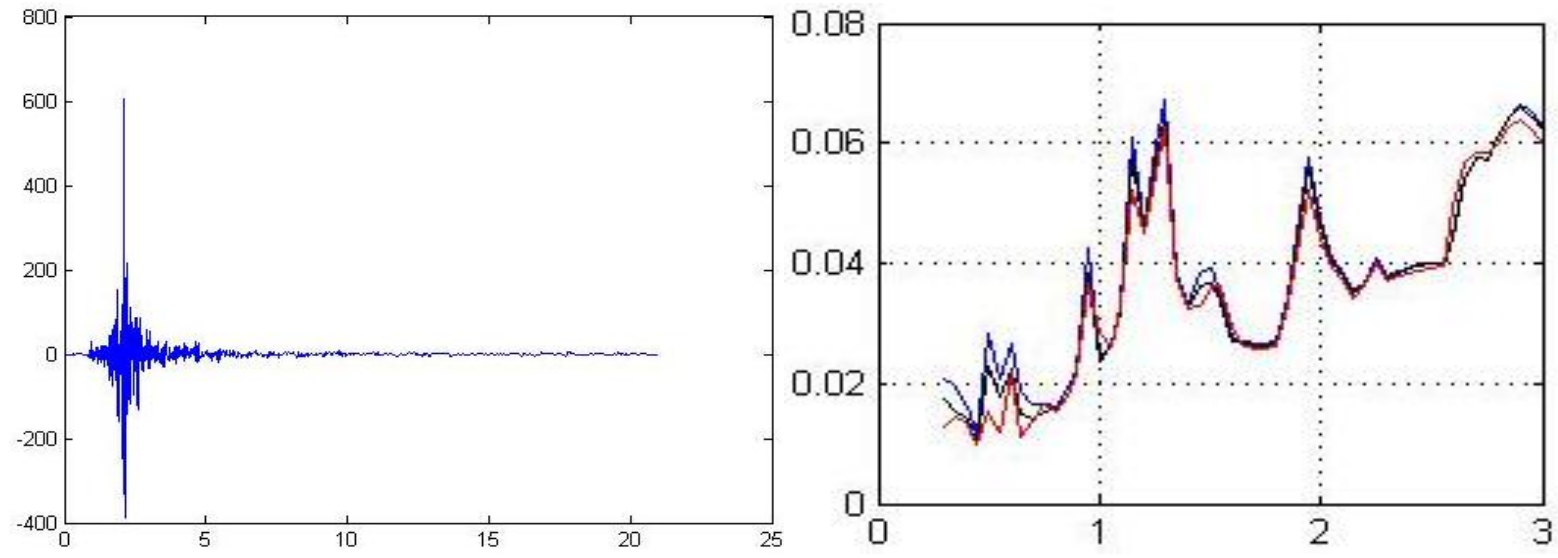

Figure 9. Accelerogram (in Gal units) and displacement spectra (in inches) of the Cape Mendocino earthquake obtained by exact (in red) and simplified methods (in blue and black) 

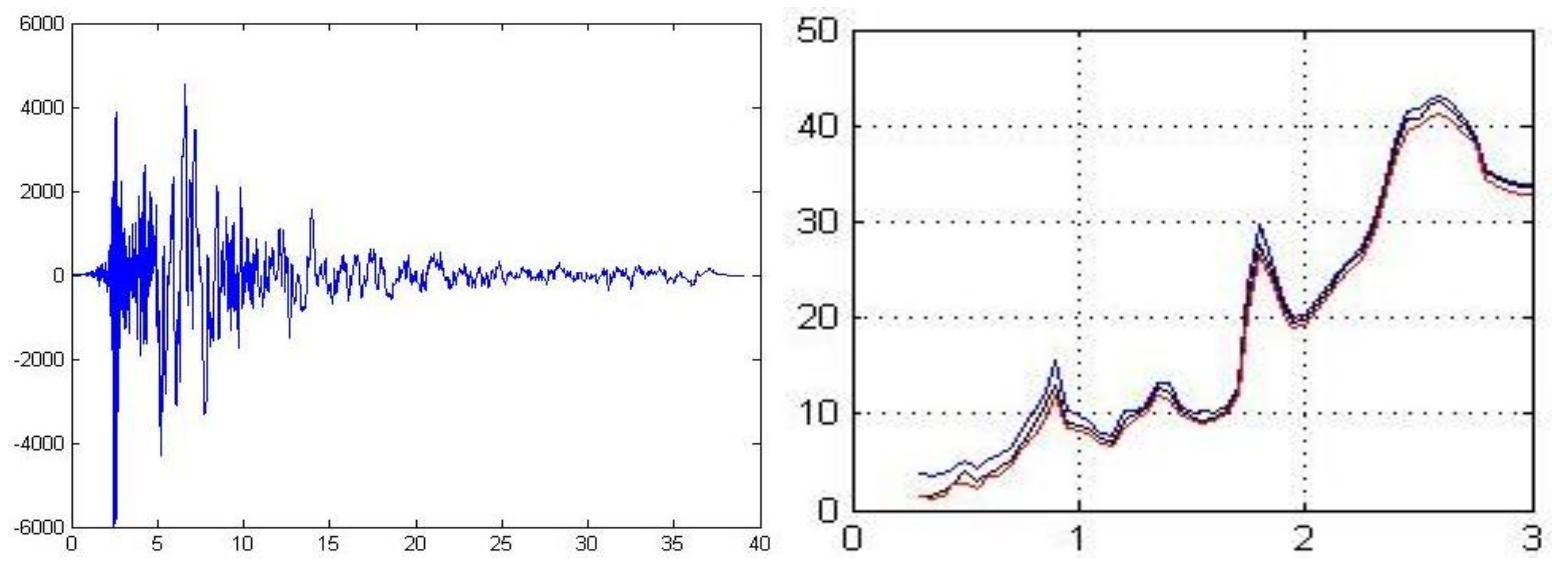

Figure 10. Accelerogram (in Gal units) and displacement spectra (in inches) of the Imperial Valley earthquake obtained by exact (in red) and simplified methods (in blue and black)
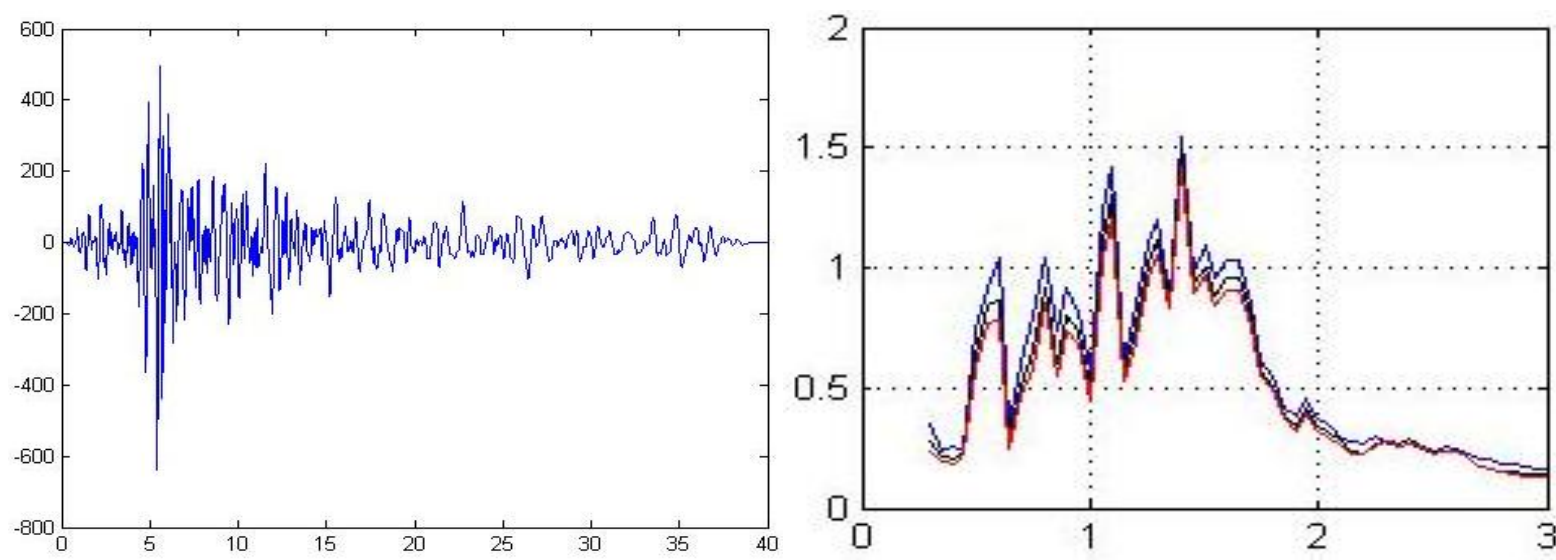

Figure 11. Accelerogram (in Gal units) and displacement spectra (in inches) of the Humbolt Bay earthquake obtained by exact (in red) and simplified methods (in blue and black)
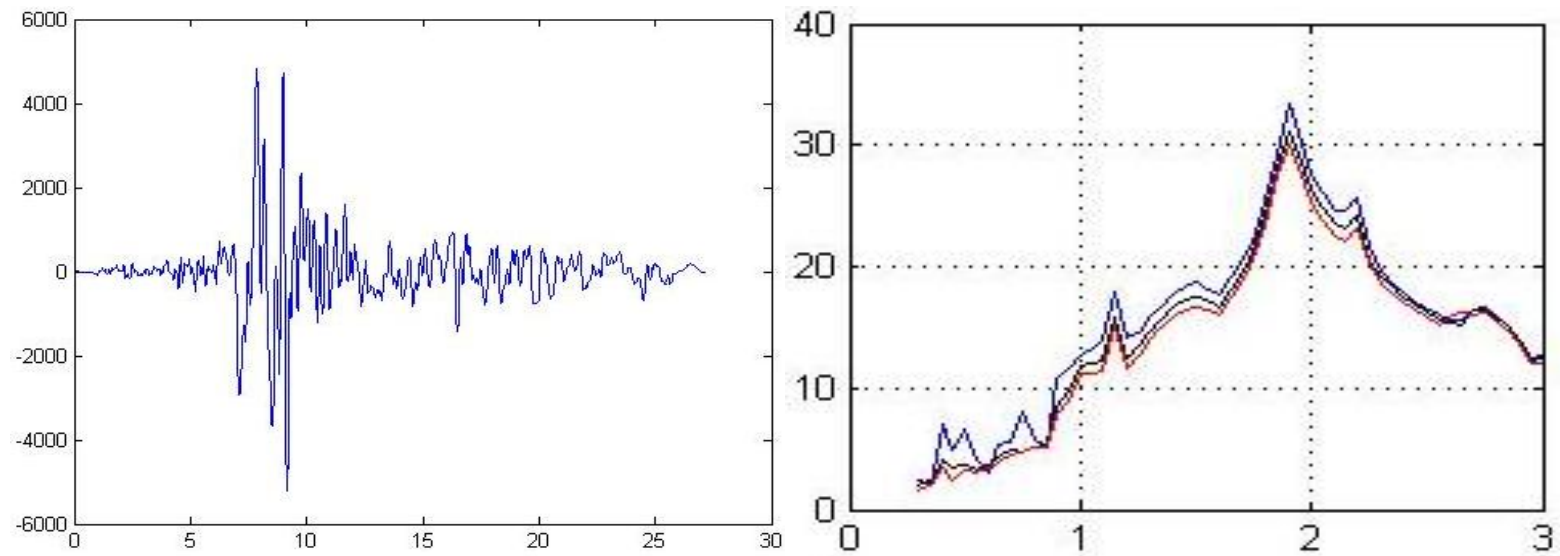

Figure 12. Accelerogram (in Gal units) and displacement spectra (in inches) of the Kocaeli earthquake obtained by exact (in red) and simplified methods (in blue and black)

It can be seen in Figures 6 to 12 that for most of the employed earthquakes the simplified method results in a very good approximation of the displacement response spectrum. As expected the amount of error is relatively high in the range of shorter periods, but in the range of longer periods, results of the exact and simplified method, particularly by double impulse simplification are very close. 


\section{CONCLUSIONS}

Based on the numerical results, obtained by using the accelerograms of several earthquakes, which cover a wide range of frequency content, it can be said that the proposed simplification method leads to very good approximation of the displacement response values, with an average error of less than $10 \%$, particularly when the double impulse simplification (considering two impulses between each pair of the zero-crossing points of the accelerogram) is used. Regarding that the number of equivalent impulses, even in the case of double impulse simplification, is much less than the number of total time steps of the digitized accelerograms, the simplified method results in drastic reduction in the required time for THA.

In some cases, particularly for short period systems subjected to accelerograms, which contain high frequencies, the amount of error in peak responses may be inacceptable. In such cases using three equivalent impulses instead of two for the parts of accelerogram between each pair of its zero-crossings, can improve the precision of the simplification method, while keeps the required time still very little, comparing to the required time for the conventional THA methods.

\section{REFERENCES}

[1] W. Y. L. Wang, Structural instability during earthquakes and accelerogram simplification, Ph.D. Dissertation, Michigan University, Ann Arbor, USA, 1975.

[2] Pastsakorn Kitiyodom, Ryuuici Sonoda, Tatsunori Matsumoto, Simplified Dynamic Analysis of Piled Raft Foundation Subjected to Earthquake Load, Proceedings of JIBAN: The 39th Japan National Conference on Geotechnical Engineering, 2004.

[3] S. Ali Ghafari Oskoei and Ghyslaine McClure, Simplified Dynamic Analysis Methods for Guyed Telecommunication Masts under Seismic Excitation, Proceedings of the 2009 Structures Congress, Austin, Texas, April 30-May 2, 2009

[4] J. L. Domingues Costa, R. Bento, V. Levtchitch \& M. P. Nielsen, Simplified non-linear time-history analysis based on the Theory of Plasticity, Proceedings of the 5th Conference on Earthquake Resistant Engineering Structures (ERES 2005), Dublin, July 2005.

[5] A. Soroushian, A technique for time integration analysis with steps larger than the excitation steps, Communications in Numerical Methods in Engineering, Special Issue, 24 (12), pp. 2087-2111, 2008.

[6] Alireza Faroughi and Mahmood Hosseini, Simplification of Earthquake Accelerograms for Quick Time History Analyses by Using Their Modified Inverse Fourier Transforms, Proceedings of the Twelfth East Asia-Pacific Conference on Structural Engineering and Construction (EASEC-12), Hong Kong Special Administration Region, China, 24-26 January 2011.

[7] Iman Mirzaei, Simplification of Earthquake Accelerograms for Rapid Time History Analysis Based on the Impulsive Load Concept, M.Sc. Thesis under supervision of Professor Mahmood Hosseini, Earthquake Engineering Department, Science and Research Branch of the Islamic Azad University (IAU), Tehran, Iran, 2013. 